\title{
MASTER SLAVE VECTOR CONTROLLED DOUBLE INDUCTION MOTOR USING UNITY POWER FACTOR CONTROLLED PWM RECTIFIER
}

\author{
G. Hari Krishna ${ }^{1}$, V. L. N. Sastry ${ }^{2}$ \\ ${ }^{I}$ M. Tech Scholar, ${ }^{2}$ Assistant Professor, Electrical and Electronics Engineering, SASI Institute of Technology and \\ Engineering, Andhra Pradesh, India, harikrish213@gmail.com, sastry@sasi.ac.in
}

\begin{abstract}
In the recent days most of the industries uses Induction motors as the primary loads. In order to meet the total load requirement multiple motors are used. In this paper two Vector Controlled (VC) Induction Motors and a double closed loop PWM rectifier are used to explain the operation of Master Slave Configuration. The work mainly concentrates on the operation of a Unity Power factor Controlled (UPFC) PWM Rectifier as the input source for both the Vector Controlled Induction Motors. This UPFC PWM Rectifier uses two closed loop pi control algorithms the inner loop controls the current and the outer loop controls the DC voltage. The proposed model is simulated in Matlab/ Simulink and the results shows good synchronization for two induction motors operated in master slave configuration.
\end{abstract}

Keywords: Vector Control, Induction Motor, PWM Rectifier, and Unity Power Factor Control

\section{INTRODUCTION}

In recent years induction motors are widely used in industries due to theirs advantages such as speed capability, robustness, cheapness and ease of maintenance. When the induction motor is operated in oriented control scheme it can compete with dc motor in high performance applications [1]. Due to the perfect decoupling control of flux and electromagnetic torque in the vector control of induction motor, it gains great interest in many industrial applications.

In this paper one of the motor is operated master and the other as slave, the speed of the master motor is a reference signal in a closed loop control system which can control the speed of slave motor and tract the speed of master.

\section{UNITY POWER CONTROL METHOD OF PWM}

\section{RECTIFIER}

Figure 1 gives the basic structure of PWM rectifier ea (t), eb $(\mathrm{t})$, ec (t) are the three phase voltages. $\mathrm{L}$ is the filter inductance. $\mathrm{R}$ is the equivalent resistance.$c$ is the support capacitance of $\mathrm{dc}$ side. RL IS the load resistance and EL is the load voltage [2].

When the load force voltage is either zero or less than DC voltage across the capacitor then the rectifier operates in rectifier mode otherwise in active inverter mode.

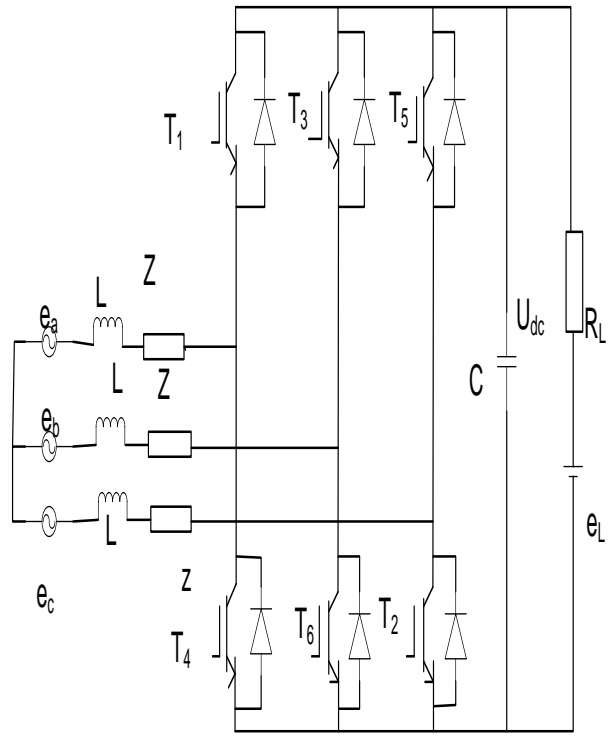

Fig.1 The structure of PWM rectifier

Figure 2 shows the block diagram unity power factor control of the PWM rectifier. This controller uses double closed loop PI control, inner PI loop control the three phase input current method controller by unity power factor control and the output DC voltage is controlled by outer PI loop [3]. 


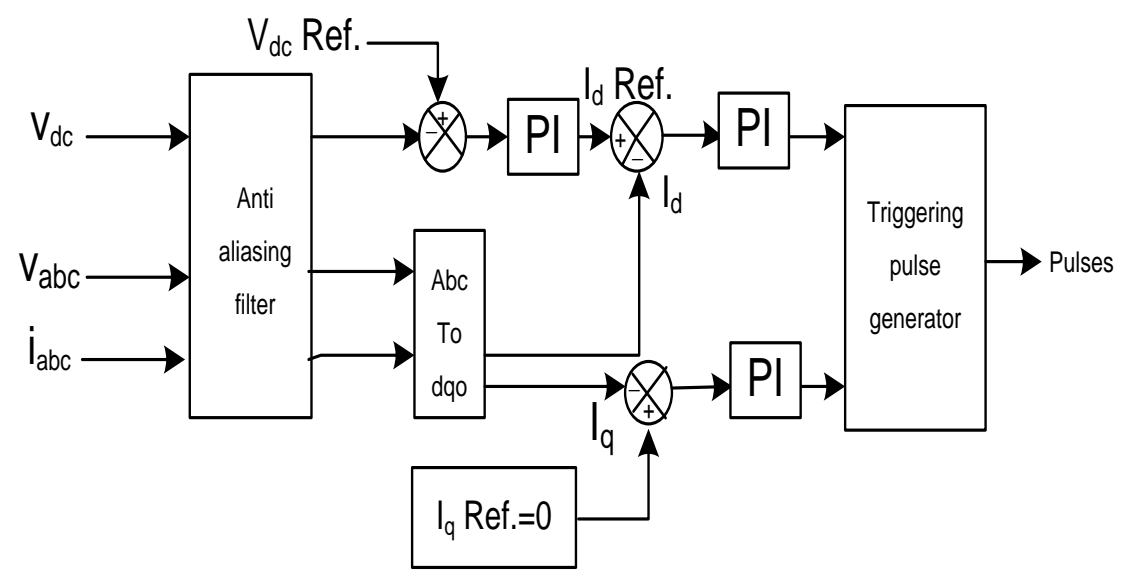

Fig.2 The unity power factor control method of PWM rectifier

\section{VECTOR CONTROL OF INDUCTION MOTOR}

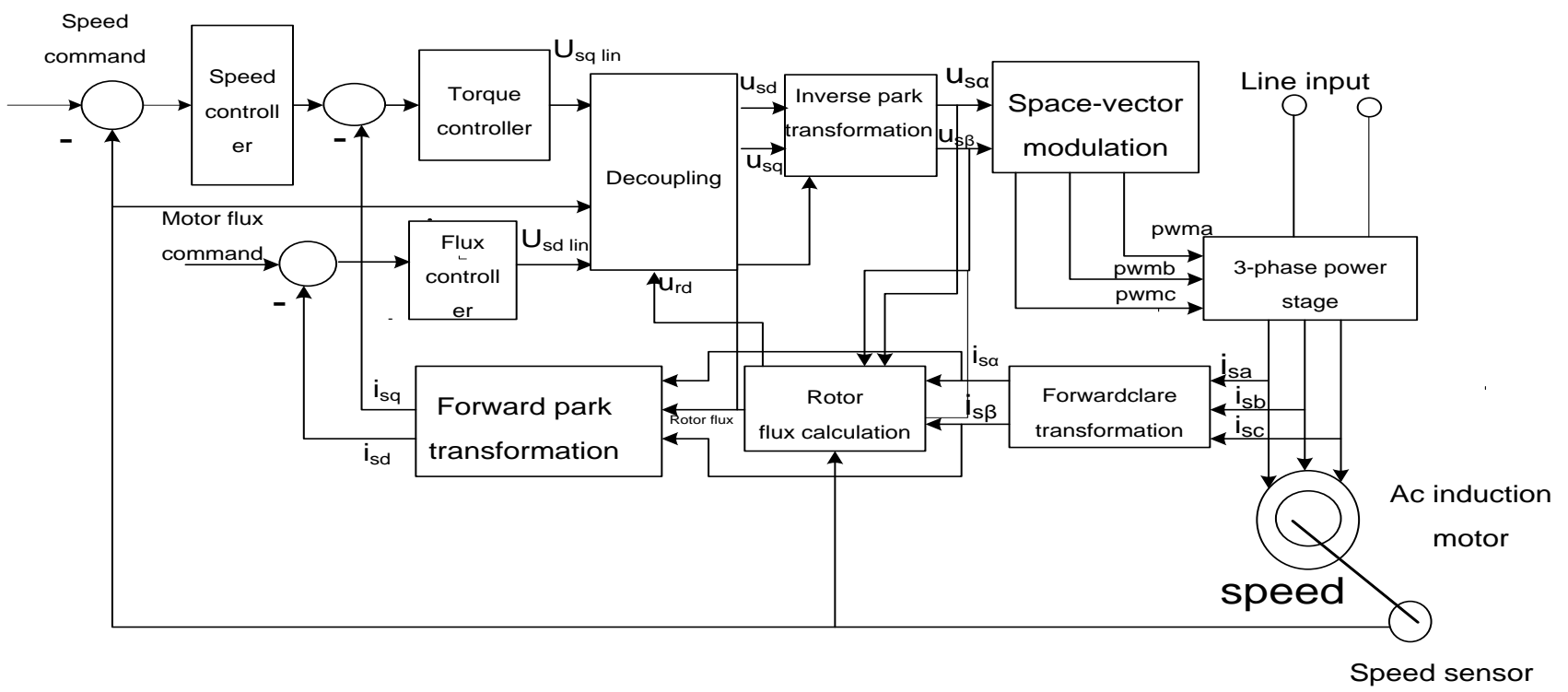

Fig. 3 Block Diagram of Vector controlled Induction Motor

It is the most popular control technique of ac induction motor. In this technique stator current of the induction machine are separated into dq co ordinate system. The direct axis (d) is aligned with the rotor flux space vector .The q-axis component of the rotor flux space vector is always zero.

$\psi_{r p}=0$ and $\frac{d}{d t} \psi_{r q}$

\subsection{Block Diagram of Vector Control}

Figure 3 shows basic structure of the vector control AC induction motor. The procedure for performing vector control is as follows [4].

- Measuring motor quantities (phase voltages and current)

- Covert them to 2-phase system $(\alpha, \beta)$ using Clarke transformation 
- Calculation of rotor flux space vector magnitude and position angle

- Transform stator currents to dq system using parks transformation

- The stator currents $i_{\text {sd }}, i_{s q}$ which will produce flux and torque respectively are controlled separately

- By using a decoupling block output stator voltage space vector is calculated

- Transform output stator voltage space vector to $\mathrm{dq}$ system using inverse park transformation

- By using a space vector modulation output three phase voltages is generated.

\subsection{Forward and Inverse Clarke Transformation}

Assume a-axis and $\alpha$ axis in same direction

There

$$
\begin{aligned}
& i_{s \alpha}=k\left[i_{s \alpha}-\frac{1}{2} i_{s b}-\frac{1}{2} i_{s c}\right] \\
& i_{s \beta}=k \frac{\sqrt{3}}{2}\left(i_{s b}-i_{s c}\right)
\end{aligned}
$$

Where

$$
\begin{aligned}
& i_{s a}=\text { actual current of the motor phase A [A] } \\
& i_{s b}=\text { actual current of the motor phase B [A] } \\
& i_{s \alpha, \beta}=\text { actual current of the motor phase C [A] }
\end{aligned}
$$

For non power invariant Transformation $\mathrm{K}=2 / 3$

The inverse Clarke Transformation for the value of $K=2 / 3$ Is given by

$$
\begin{aligned}
& i_{s \alpha}=i_{s a} \\
& i_{s \beta}=\frac{1}{\sqrt{3}} i_{s a}+\frac{2}{\sqrt{3}} i_{s b} \\
& i_{s a}=i_{s \alpha} \\
& i_{s b}=-\frac{1}{2} i_{s \alpha}+\frac{\sqrt{3}}{2} i_{s \beta} \\
& i_{s c}=-\frac{1}{2} i_{s \alpha}-\frac{\sqrt{3}}{2} i_{s \beta}
\end{aligned}
$$

\subsection{Forward and Inverse Park Transformation}

Because the control process is not possible in stator reference frame these are shifted to dq reference frame

$$
\begin{gathered}
i_{s d}=i_{s \alpha} \cos \theta_{\text {filed }}+i_{s \beta} \sin \theta_{\text {filed }} \\
i_{s q}=-i_{s \alpha} \sin \theta_{\text {field }}+i_{s \beta} \cos \theta_{\text {flied }}
\end{gathered}
$$

Where

$$
\begin{aligned}
& \sin \theta_{\text {fleld }}=\frac{\psi_{r \beta}}{\psi_{r d}} \\
& \cos \theta_{\text {flied }}=\frac{\psi_{r \alpha}}{\psi_{r d}} \\
& \psi_{r d}=\longdiv { \psi _ { r \alpha } ^ { 2 } + \psi _ { r \beta } ^ { 2 } }
\end{aligned}
$$

Inverse park transformation is given by

$$
\begin{aligned}
& i_{s \alpha}=i_{s d} \cos \theta_{\text {flied }}-i_{s q} \sin \theta_{\text {flied }} \\
& i_{s \beta}=i_{s d} \sin \theta_{\text {flied }}+i_{s q} \cos \theta_{\text {flied }}
\end{aligned}
$$

\subsection{Rotor Flux Model}

In $\mathrm{AC}$ induction motor vector control magnitude of rotor flux space vector place a vital role. To obtain rotor magnetic flux space vector here the process of monitoring rotor speed, stator voltage. And currents are utilized.

By solving the following equation, rotor flux space vector can be obtained

$$
\begin{array}{r}
{\left[(1-\sigma) T_{s}+T_{r}\right] \frac{d \psi_{r \alpha}}{d t}=\frac{L_{m}}{R_{s}} u_{s \alpha}-\psi_{r \alpha}-\omega T_{r} \psi_{r \beta}-\sigma L_{m} T_{s} \frac{d i_{s \alpha}}{d t}} \\
\ldots \ldots .(9) \\
{\left[(1-\sigma) T_{s}+T_{r}\right] \frac{d \psi_{r \beta}}{d t}=\frac{L_{m}}{R_{s}} u_{s \beta}-\psi_{r \beta}-\omega T_{r} \psi_{r \alpha}-\sigma L_{m} T_{s} \frac{d i_{s \beta}}{d t}}
\end{array}
$$

Where

Ls=self-inductance of the stator $[\mathrm{H}]$

$\mathrm{Lr}=$ self-inductance of the rotor $[\mathrm{H}]$

$\mathrm{Lm}=$ magnetizing inductance $[\mathrm{H}]$

$\mathrm{Rs}=$ Resistance of a stator phase winding $[\mathrm{Ohm}]$

$\mathrm{Rr}=$ Resistance of a rotor phase winding [Ohm]

$\omega=$ Angular Rotor speed [rad. s-1]

$\mathrm{pp}=$ Number of motor pole pairs

$T_{r=} \frac{L_{r}}{R_{r}}=$ Rotor Time constant [s] 


$$
\begin{aligned}
& T_{s}=\frac{L_{s}}{L_{r}}=\text { Stator Time Constant }[\mathrm{s}] \\
& \sigma=1-\frac{L_{m}^{2}}{L_{s} L_{r}}=\text { Resultant Leakage Constant [-] }
\end{aligned}
$$

\subsection{Decoupling Circuit}

The Purposes of rotor flux -oriented vector controls, the direct axis stator current and quadrature axis stator current must be controlled independently. The stator currents are decoupled control and stator voltages are not considered. The stator voltage decoupled and stator current components isd and Isq are indirectly controlling of terminal voltage of induction

- $\quad$ linear components $u_{s d}^{\text {lin }}, u_{s q}^{\text {lin }}$

- Decoupling components $u_{s d}^{\text {decouple }}, u_{s q}^{\text {decouple }}$

The equations are decoupled as follow:

$u_{s d}=u_{s d}^{\text {lin }}+u_{s d}^{\text {decouple }}=\left[k_{R} i_{s d}+k_{L} \frac{d}{d t} i_{s d}\right]-\left[\omega_{s} k_{L} i_{s q}+\frac{\psi_{r d} l_{m}}{l_{r} t_{r}}\right]$

$u_{s q}=u_{s d}^{\text {lin }}+u_{s d}^{\text {decouple }}=\left[k_{r} i_{s q}+k_{l} \frac{d}{d t} i_{s d}\right]+\left[\omega_{s} k_{l} i_{s d}+\frac{l_{m}}{l_{r}} \omega \psi_{r d}\right]$

Where

$K_{R}=R_{S}+\frac{L_{m}^{2}}{L_{r}^{2}} R_{r}$

$K_{L}=L_{S}-\frac{L_{m}^{2}}{L_{r}}$

$u_{s d}^{l i n}=K_{R} i_{s d}+K_{L} \frac{d}{d t} i_{s d}$

$u_{s q}^{l i n}=K_{R} i_{s q}+K_{L} \frac{d}{d t} i_{s q}$

The decoupling components

$u_{s d}^{\text {decouple }}=-\left(\omega_{s} K_{L} i_{s q}+\frac{L_{m}}{L_{r} T_{r}} \psi_{r d}\right)$ $u_{s q}^{\text {decouple }}=\left(\omega_{s} K_{L} i_{s d}+\frac{L_{m}}{L_{r}} \omega \psi_{r d}\right)$

\subsection{Space Vector Modulation}

It can directly transform the stator voltage vectors $\alpha, \beta$ coordinate system to pulse width modulation signals. It is more valid for transformation from $\alpha, \beta$ - coordinate system, this technique are good results. In the basic principle of standard space vector modulation explained $d$ with the help of power stage schematic diagram

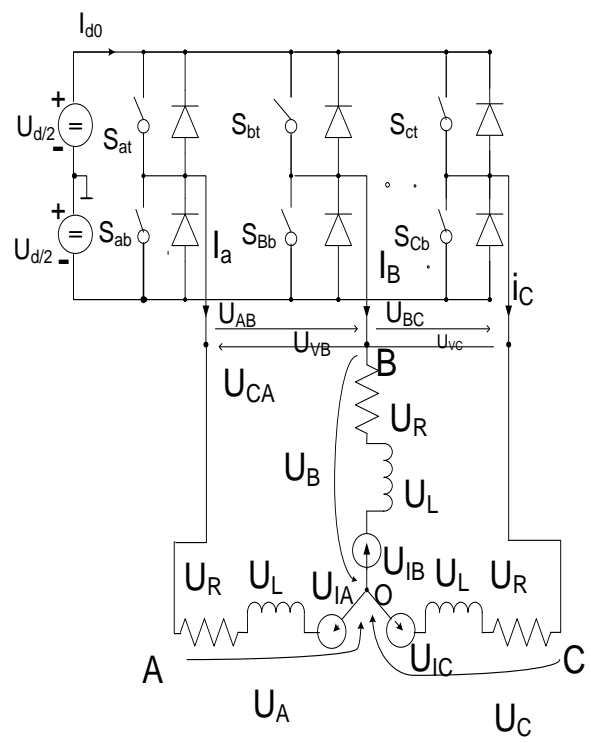

Fig.4 power stage schematic diagram

Table1 is there are six non-zero vectors UO, U60, U120, U180, U240, U300 and two zero vectors O000 andO111, defined in $\alpha$, $\beta$ coordination. The combination of ON/OFF states of power state switches for each voltage vector by the three digital numbers is parenthesis.

Figure 4 as the eight possible switching states are possible and given by combinations of the corresponding power switches the value ONE means upper switch is ON and bottom switches OFF.

The value ZERO means upper switches are OFF and bottom switches are ON. Within the result in output line - to - line voltage, phase voltage, voltage vector

Table1 Switching Patterns and Resulting Instantaneous Line to-Line and Phase Voltages

\begin{tabular}{|l|l|l|l|l|l|l|}
\hline $\mathrm{abc}$ & $\mathrm{Ua}$ & $\mathrm{Ub}$ & $\mathrm{Uc}$ & $\mathrm{Uab}$ & $\mathrm{Ubc}$ & $\mathrm{Uca}$ \\
\hline 000 & 0 & 0 & 0 & 0 & 0 & 0 \\
\hline 100 & $2 \mathrm{Udc} / 3$ & $-\mathrm{Udc} / 3$ & $-\mathrm{Udc} / 3$ & $\mathrm{Udc}$ & 0 & $-\mathrm{Udc}$ \\
\hline
\end{tabular}




\begin{tabular}{|l|l|l|l|l|l|l|}
\hline 110 & $\mathrm{Udc} / 3$ & $\mathrm{Udc} / 3$ & $2 \mathrm{Udc} / 3$ & 0 & $\mathrm{Udc}$ & $-\mathrm{Udc}$ \\
\hline 010 & $-\mathrm{Udc} / 3$ & $2 \mathrm{Udc} / 3$ & $-\mathrm{Udc} / 3$ & $-\mathrm{Udc}$ & $\mathrm{Udc}$ & 0 \\
\hline 011 & $2 \mathrm{Udc} / 3$ & $\mathrm{Udc} / 3$ & $\mathrm{Udc} / 3$ & $-\mathrm{Udc}$ & 0 & $\mathrm{Udc}$ \\
\hline 001 & $-\mathrm{Udc} / 3$ & $-\mathrm{Udc} / 3$ & $2 \mathrm{Udc} / 3$ & 0 & $-\mathrm{Udc}$ & $\mathrm{Udc}$ \\
\hline 101 & $\mathrm{Udc} / 3$ & $-2 \mathrm{Udc} / 3$ & $\mathrm{Udc} / 3$ & $\mathrm{Udc}$ & $-\mathrm{Udc}$ & 0 \\
\hline 111 & 0 & 0 & 0 & 0 & 0 & 0 \\
\hline
\end{tabular}

It is a technique and direct bridge between vector control and PWM.

1. Sector identification.

2. Space voltage vector decomposition into direction of sector base vector $\mathrm{u}_{\mathrm{x}}, \mathrm{u}_{\mathrm{x} \pm 60}$.

3. PWM duty cycle calculation

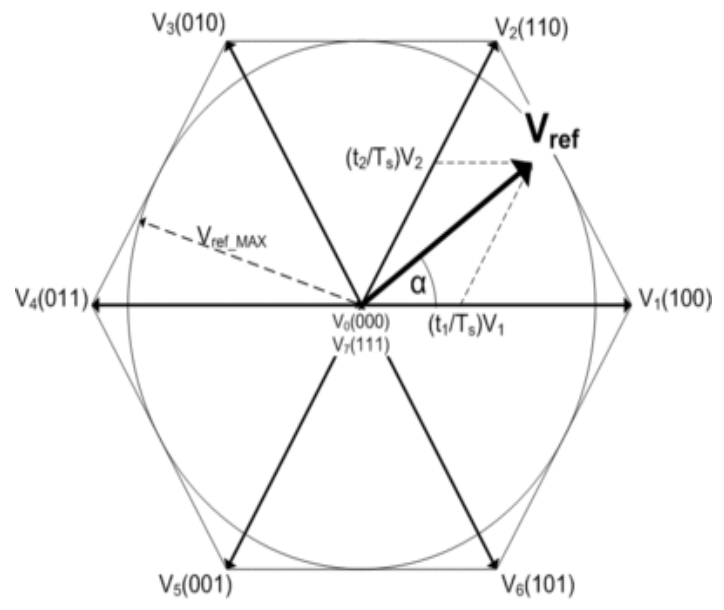

Fig.5 Base Space Vector and Voltage Vector projection

The principle of the SVM

$$
T_{P W M} \cdot U_{S[\alpha, \beta]}=T_{1} \cdot U_{X}+T_{2} \cdot U_{X \pm 60}+T_{0} \cdot\left(O_{000} \vee O_{111}\right)
$$

$T_{P W M}=T_{1}+T_{2}+T_{0}$

Where

T0, T1, T2 =Time periods

$\mathrm{U} \mathrm{s}(\alpha, \beta)=$ Space voltage vector

The direction of the sector base vector $\mathrm{Ux}, \mathrm{Ux} \pm 60$

$$
\begin{aligned}
& T_{P W M} \cdot U_{S X}=T_{1} U_{X} \\
& T_{P W M} \cdot U_{S[X \pm 60]}=T_{2} \cdot U_{X \pm 60}
\end{aligned}
$$

$$
\begin{aligned}
& T_{1}=\frac{\left|U_{S X}\right|}{\left|U_{X}\right|} T_{P W M} \quad \text { Vector Ux } \\
& T_{2}=\frac{\left|U_{S X}\right|}{\left|U_{X \pm 60}\right|} T_{P W M} \quad \text { Vector ux } \pm 60 \\
& T_{0}=T_{P W M}-\left(T_{1}+T_{2}\right)
\end{aligned}
$$

\section{MASTER SLAVE CONTROL TECHNIQUE}

This technique is used in the process of synchronization Double motors. The main characteristic is that reference speed given to the master motor produces the corresponding revolving speed and it will acts as a reference speed of slave motor. Any noise or the changes occurred in a master motor will reflected and tracked by the slave motor [5].

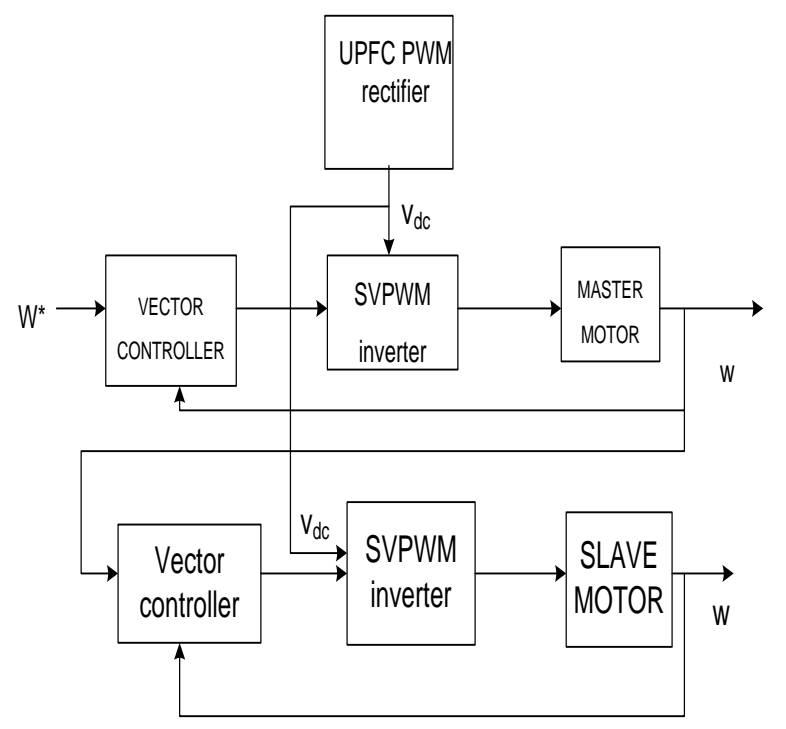

Fig.6 Block diagram of master slave control technique

The indirect vector control reference speed and load torque applied to motor shaft can be selected both switch blocks, in order to either constant value or step function. 


\section{MODELING AND SIMULATION RESULTS}

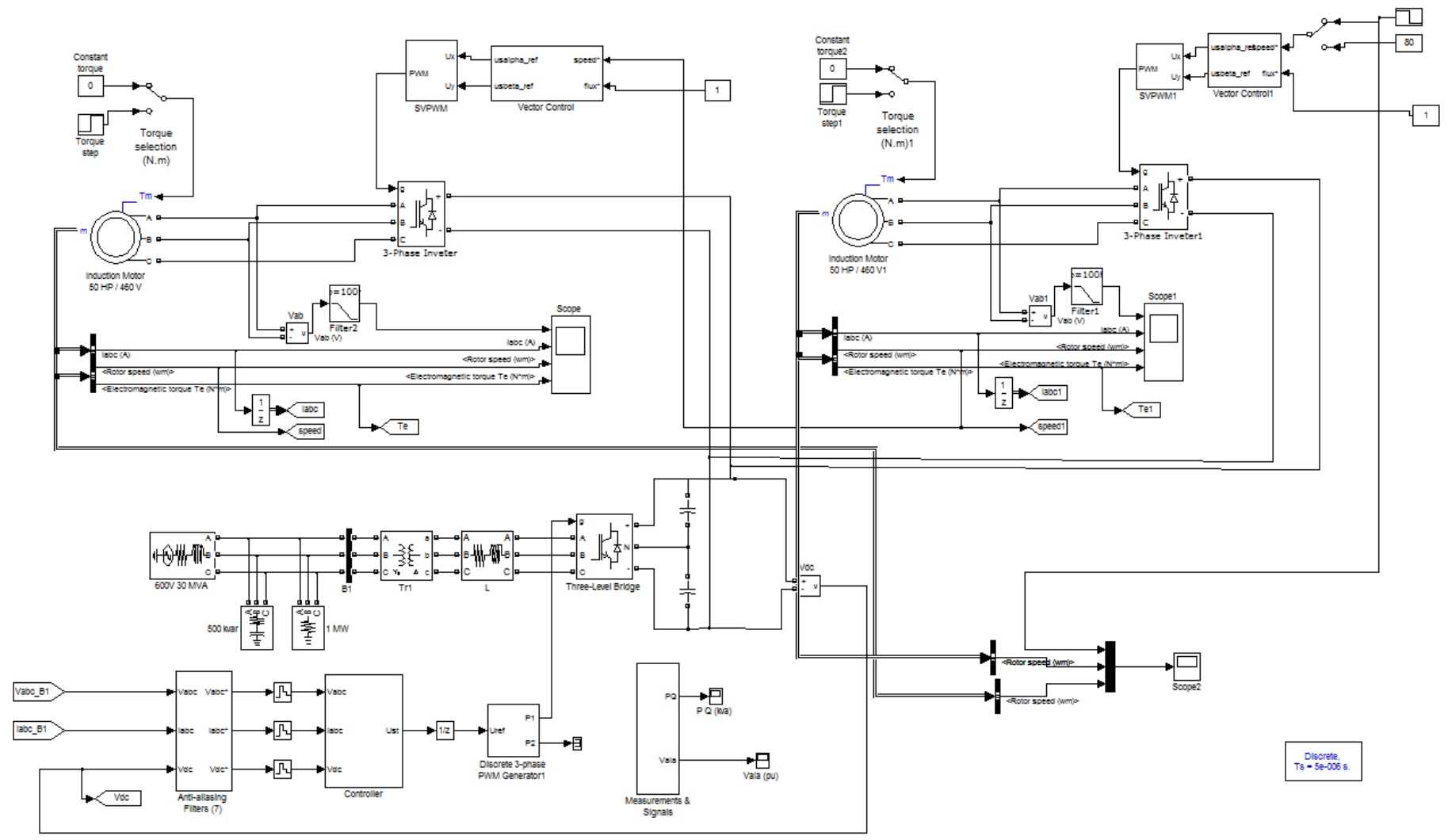

Fig.7 Matlab Simulink model for Master Slave Vector controlled Double induction motor using UPF controlled PWM rectifier

The figure 7 represents the basic building model for a Master Slave vector controlled Double Induction motor fed by a Unity Power Factor Controlled PWM Rectifier.

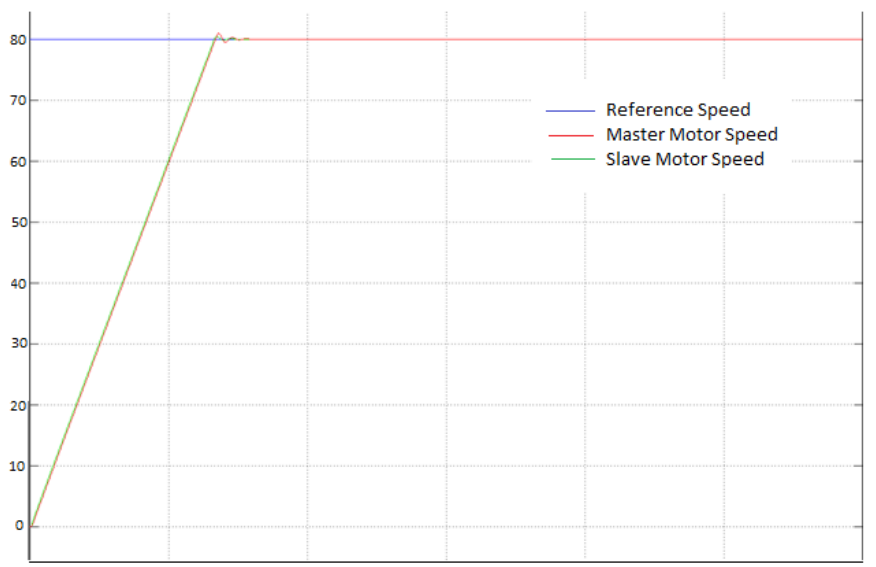

Fig.8 Rotor speed response for a master and slave motors with the constant reference speed
Figure 8 represents the speed response of the master motor and the slave motor with the constant reference speed of $80 \mathrm{rpm}$.

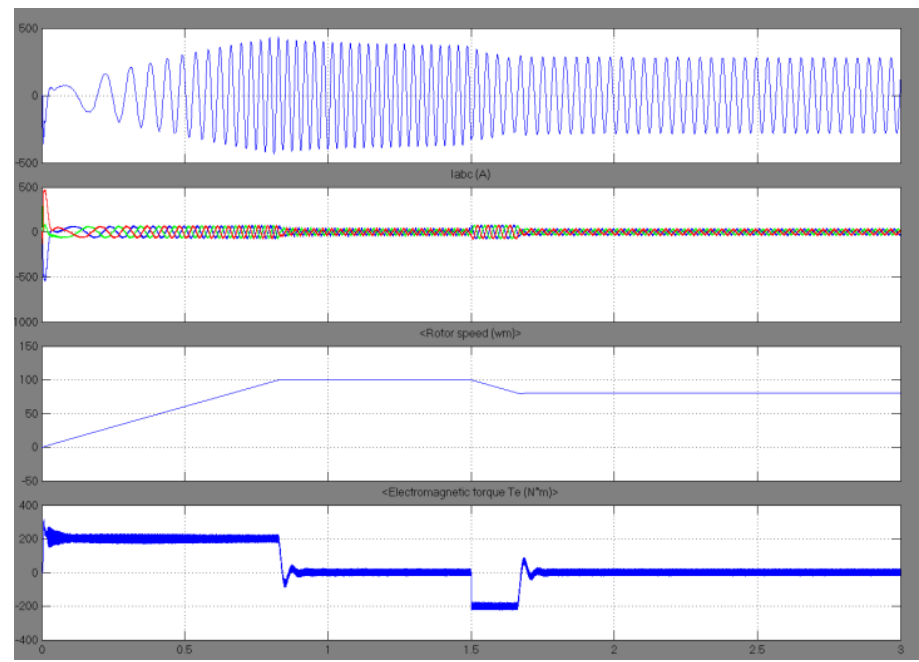

Fig.9 Voltage, Current, Rotor speed and Torque for a Master Motor and Slave motor 
Figure 9 represents the voltage, current, Rotor speed and Torque for a Master motor and slave motor for the reference speed changing from $100 \mathrm{rpm}$ to $80 \mathrm{rpm}$ at $1.5 \mathrm{sec}$

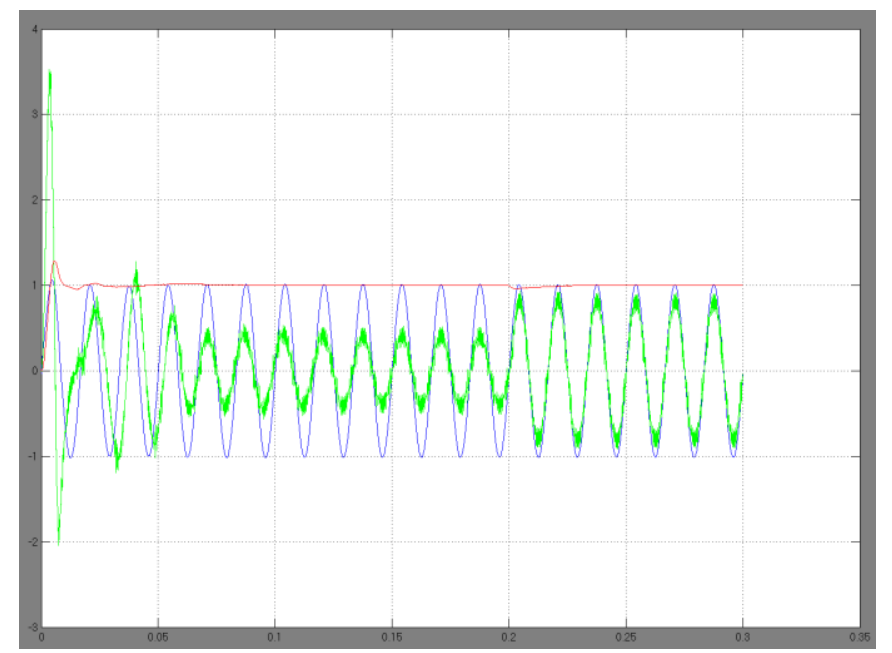

Fig.10 Output voltage, current and dc voltage of Unity Power Factor Control PWM rectifier

Figure 10 describes output voltage, current and dc voltage for a Unity Power Factor Control PWM rectifier. Here at time 0.2 sec the current is in phase with the voltage and maintain unity power factor.

\section{CONCLUSIONS}

In this work all the parameters for the master and slave motors are investigated, the technique is well synchronized for double induction motor. In industry applications the synchronization of double induction motors plays a vital role. The master slave double induction motor technique has faster speed response, short settling time, robustness, and less over shoot.

\section{ACKNOWLEDGEMENTS}

The authors would like to express special gratitude and thank all the teaching staff of the electrical department in SASI institute of technology and engineering for their good support. Also extend their sincere thanks to the Head of the Department for his moral and constant support in completing this work.

\section{REFERENCES}

[1] Hamid M, Metawally B, Annis WR, performance analysis of pv pumping systems using switched reluctance motor drives solar energy, 19956;56(2):161.

[2] Zhang jinggang, Yang BO, Zeng guang and Tion Yangyang, A unity power factor control method of PWM rectifier, power and energy engineering conference (APPEEC), 2012 Asia-pacific, pp 1-4.

[3] Zhang Chongwei, Zhang Xing, "PWM rectifier and its control” Bijing mechanical industry press, 2003
[4] Jaroslay Lepka, Petr Stekl, 3-phase AC induction motor vector control using a 56F80x, 56F8100 or56F8300 Device.

[5] Biao YU, Hui ZHU andChi XUE, "Research on adaptive fuzzy PID synchronous control strategy of double motor", I.J Intelligent system and applications, 2011, 5, 28-33.

\section{BIOGRAPHIES}

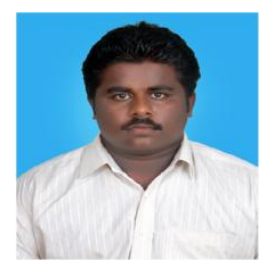

G. Hari Krishna received the B.Tech. degree in Electrical and Electronics Engineering from Sai Spurthi Institute of Engineering and Technology, Sathupally, Khammam (Dt.), A.P, India, in 2010. Currently he is pursuing M.Tech. in Power Electronics from SASI Institute of Technology and Engineering College, Tadepalligudem, West Godavari (DT), A.P, India. His interested areas are in the field of Renewable Energies, Power Converters, and power electronics.

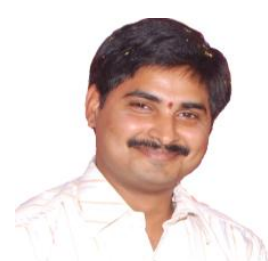

V.L.N. Sastry completed B.Tech with specialization of E.E.E in Sasi Institute of Technology and Engineering in the year 2008. He completed M.Tech in the stream of Instrumentation and control systems JNTU Kakinada in the year 2010. He has been working as an Assistant Professor in the department of E.E.E in SASI Institute of Technology and Engineering at Tadepalligudem for last 3 yrs. He is presently a member of International Association of Engineers (IAENG) and International Association of Computer Science and Information Technology (IACSIT). He has various publications in reputed International Journals on image fusion, Power Electronics and Power systems. His areas of research include neural networks and fuzzy control, image fusion, power electronics. 